\title{
Preparation and characterization of environment friendly used rubber powder modified pulp sediments composites
}

\author{
Weili Wu $\cdot$ Jing Zhang
}

Received: 8 November 2011 / Accepted: 7 August 2012/Published online: 29 August 2012

(C) The Author(s) 2012. This article is published with open access at Springerlink.com

\begin{abstract}
In recent years, with growing contradiction between energy supply and demand, the more and more high demand of the environmental protection is needed. The work represented an environment friendly method for recycling of waste rubber and pulp sediment that a new composite material was prepared using pulp sediment as the matrix, used rubber powder as the toughening agent, and sawdust as the reinforcement. The effects of used rubber powder content on the mechanical properties of the pulp sediment and sawdust/pulp sediment were studied by measuring Shore A hardness, tensile stress, and elongationat-break. The morphology of used rubber powder/pulp sediment composites was analyzed by scanning electronic microscopy and transmission electron microscopy. The curing conditions were also discussed. The results showed when the used rubber powder/pulp sediment mass ratio was $8 / 100$, the used rubber powder/pulp sediment sample showed smooth surface, high hardness, compact structure, uniform arrangement, and good compatibility. When the pulp sediment used as the matrix, sawdust as the reinforcement, and used rubber powder as the toughening agent, the proper recipe of the composites was 100 phr pulp sediment, $30 \mathrm{phr}$ sawdust, and $10 \mathrm{phr}$ used rubber powder. The mechanical properties of the used rubber powder/pulp sediment were greater than those of pure pulp sediment and used rubber powder/sawdust/pulp sediment. The best curing conditions for the used rubber powder/pulp sediment composites were at $150{ }^{\circ} \mathrm{C}$ under $5 \mathrm{MPa}$ for $15 \mathrm{~min}$. The study on used rubber powder modified pulp sediment, exploits a new way to recycle used rubber powder and pulp
\end{abstract}

W. Wu $(\bowtie) \cdot$ J. Zhang

College of Materials Science and Engineering, Qiqihar University, Qiqihar 161006, People's Republic of China e-mail: wuweili2001@163.com sediment, not only benefit environment purification, but also reduce cost of sheet materials, and develops a new way for the economy and environment protection.

Keywords Pulp sediments - Used rubber powder . Preparation $\cdot$ Characterization

\section{Introduction}

In recent years, with growing contradiction between energy supply and demand, the more and more demand of the environmental protection is needed [1]. The industrial and life waste treatments have attracted increasingly people's attention [2]. A variety of industrial production wastes contain different pollutants [3]. The industrial wastes mishandling not only cause serious environment pollution [4] but also lead to waste of resources [5]. In order to get out of the natural resource scarcity [6], the energy crisis problems and waste material pollution to the environment [7], the economic, effective recycling of the industrial wastes have always been the focus of attention in the whole society [8]. The worldwide experts have studied industrial production toward renewable resources [9] and secondary energy utilization [10].

Modern paper industry is one of the major industries. Paper and cardboard production has been used to mark a national modernization and civilization [11]. In China, the paper industry has been an important part of the national economy. According to the material forecast, paper and cardboard demand will reach $75-80$ million ton by 2015 [12]. Owing to the process technology of the Chinese papermaking industry has been relatively backward for years, the products are in low level, and environmental pollution is serious. In addition, because the papermaking 
industry is a modern industry with intensive technology and capital, the input of fixed assets is as 3 time as those of food and textile industry, The production for $1 \mathrm{t}$ pulp need $4-5 \mathrm{~m}^{3}$ raw woods. From the above, the fast growth paper industry is restricted more and more by raw material, environmental protection, capital, and other factors. Therefore, recycling waste paper pulp is particularly important.

Pulp sediment, which mainly comes from the waste paper pulp sediment, is considered in some of the plants as raw material, and is the basic materials of paper industry. The constituents of pulp sediment mainly are cellulose [13], also includes something such as hemicellulose, lignin, resin, pigment, pectin, ash, etc. Pure pulp sediment is high hardness and easy fragile. At present, it is important to produce packing box [14], the environmental protection bags [15], paper handicraft [16], low-level paper [17], and pulp molding industry [18]. As poor toughness and strength of pulp sediments products [19], the used rubber powder toughened pulp sediment and sawdust reinforced pulp sediment were studied in this work to make full use of pulp sediment.

At present, the studies on pulp sediment [20] or used rubber powder [21] are very common at home and abroad [22], but the study on their mixture has not reported. Thus, the used rubber powder and pulp sediment are mixed to make a kind of high performance-to-price ratio composites in this work.

This composite material can be used in packing boxes and plank material alternatives such as medium density board, etc. Therefore, it can save a lot of wood. The study on used rubber powder modified pulp sediment, exploits a new way to recycle used rubber powder and pulp sediment, not only benefits environment decontamination, but also reduce cost of sheet materials production, and develops a new way for the economy and environment protection.

\section{Experimental}

\section{Materials}

Pulp sediment (PS) was manufactured by Qiqihaer Fuyu Paper Ltd., China, in block shaped with diameter of 5-10 $\mathrm{mm}$ and water content of 48-51 wt \%. Used rubber powder (URP) which principally is made of waste tire, was supplied by Heilongjiang Jiarui Rubber Ltd., China, with diameter of $0.10-0.32 \mathrm{~mm}$, which its main composition is butadiene rubber and styrene butadiene rubber. Sawdust was provided by Qiqihaer Fuqiang Wood Process Factory, China, with diameter of $0.40-0.10 \mathrm{~mm}$. Sulfur, mercapto benzothiazole (accelerator M, Scheme 1a), and $N$-phenyl$\beta$-naphthylamine (antioxidant $\mathrm{D}, \quad$ Scheme $1 \mathrm{~b}$ ) were respectively supplied by Shandong Zibo Shuanggou Dongfeng Chemical Plant, Henan Kailun Chemical Ltd., and<smiles>Sc1nc2ccccc2s1</smiles>

(a)

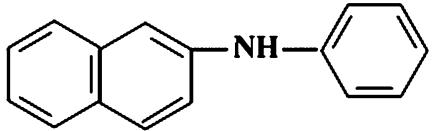

(b)
Scheme 1 Chemical formulas of (a) accelerator M and (b) antioxidant D

Jiatong Chemical Ltd. as industrial grade, in which sulfur is curing agent.

\section{Sample preparation}

In the work, the principal formulation is $100 \mathrm{phr}$ (part by mass, g) pulp sediments, $30 \mathrm{phr}$ sawdust, and $8 \mathrm{phr}$ used rubber powder, in which the contents of sulfur, accelerate $\mathrm{M}$ and antioxidant $\mathrm{D}$ are all $2 \mathrm{wt} \%$ of used rubber powder.

Initially, pulp sediments and sawdust were masticated on XK-160 two-roll mill for $3 \mathrm{~min}$ at $45-55{ }^{\circ} \mathrm{C}$, while the distance between two rolls was about $0.8 \mathrm{~mm}$. Then, the distance between two rolls was adjusted $4 \mathrm{~mm}$, and added used rubber powder at $50-60{ }^{\circ} \mathrm{C}$. After that, various ingredients were mixed in turn on the two-roll mill for 10 min according to principal formulation. At the end, cured on plate vulcanize machine (model XLB-D350 $\times 350$, The first rubber factory of Shanghai, Shanghai, China) at $150{ }^{\circ} \mathrm{C}$ under $4 \mathrm{MPa}$ for $10 \mathrm{~min}$.

\section{Measurements}

The dumb-bell shaped rubber specimens were prepared from a sheet of the vulcanizates by cutting. The mechanical properties were tested by an electronic universal testing machine (model CSS-2200, Zhongji Application Technical Institute, Changchun, China) according to ISO 37-1994. For each of the measurements, an average of at least five readings was taken. Errors in the measurement of mechanical properties were within $10 \%$. Scanning electronic microscopy (SEM) (model S-4300, Hitachi Co., Japan) was used to characterize microstructure of the composites. Transmission electron microscopy (TEM) measurements were performed using a JEOL Hitachi H-7650 (Japan) electron microscope operating at an acceleration voltage of $80 \mathrm{kV}$.

\section{Results and discussion}

Effects of used rubber powder on the pulp sediment

Effects of used rubber powder content on the properties of pulp sediment are shown in Fig. 1. It is found that the 

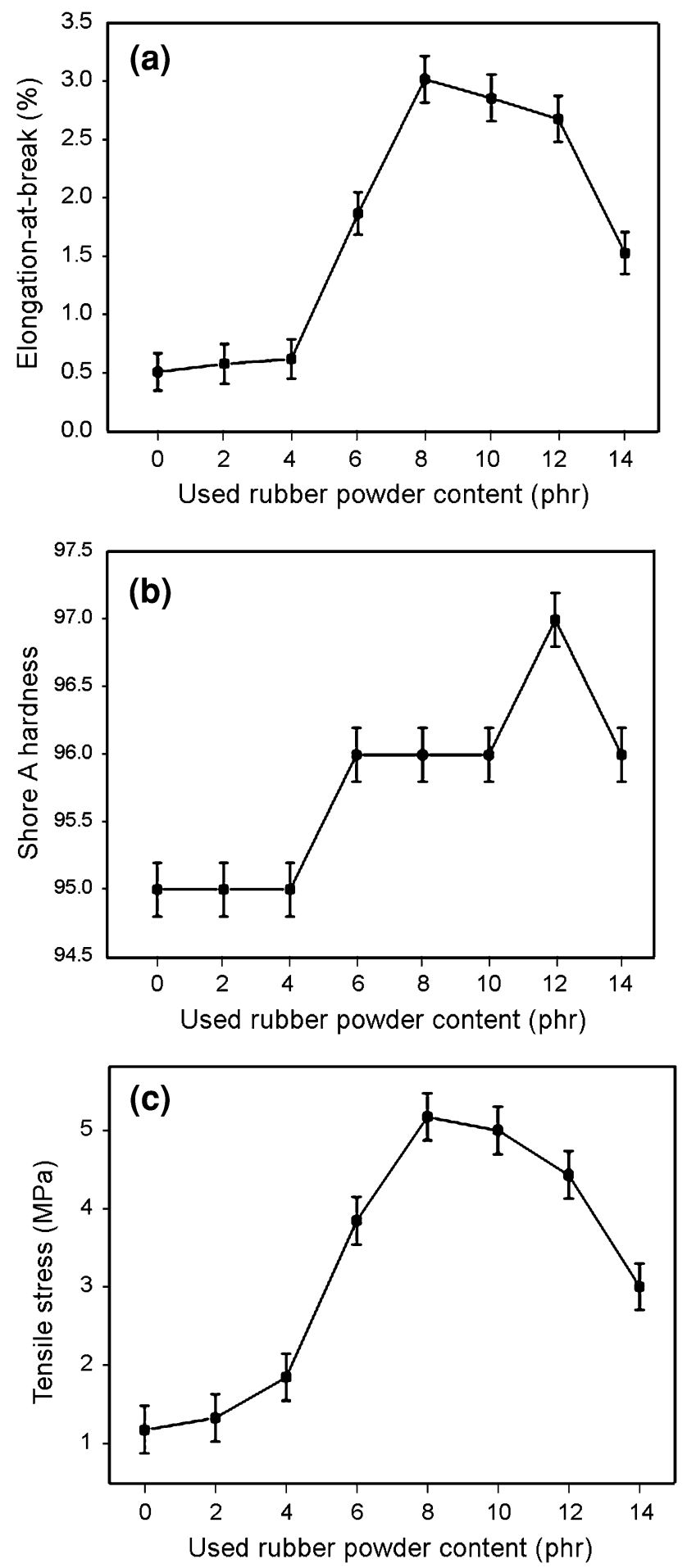

Fig. 1 Effect of used rubber powder content on the mechanical properties of pulp sediments: a elongation-at-break, b Shore A hardness, and $\mathbf{c}$ tensile stress (no sawdust)

hardness changes insignificantly when the used rubber powder's content is less than $4 \mathrm{phr}$, but tensile strength is low. The properties are improved when the used rubber powder's content increased. When used rubber powder's content is more than $8 \mathrm{phr}$, tensile stress and elongation-atbreak of the specimens decrease gradually. Tensile stress and elongation-at-break values were highest at $8 \mathrm{phr}$ used rubber powder, but hardness changes unclearly. It suggests that the properties of the used rubber powder/pulp sediment sample are good at $8 \mathrm{phr}$ used rubber powder. This is due to the used rubber powder which is made of worn out rubber products (tires, rubber shoes, etc.) its main compositions are rubber and filler. Used rubber powder increases toughness of pulp sediment, and fills the gaps of pulp sediment fibers. When the contents of used rubber powder is more than $8 \mathrm{phr}$, the excess used rubber powder is able to increase the gap between pulp sediment fibers, and results in mechanical properties decline. Therefore, $8 \mathrm{phr}$ used rubber powder is suitable for URP/PS composites.

\section{Effects of sawdust on the pulp sediments}

It was tried to use sawdust as reinforcement, the effects of sawdust on the mechanical properties of pulp sediment are shown in Fig. 2. With increasing of sawdust content, the tensile stress, elongation-at-break and Shore A hardness values of the specimens show trends in rise after restrain. When sawdust content is $30 \mathrm{phr}$, the curves present turning point. It should be considered that sawdust is powder, from which is scattered down in wood processing [23], and is similar to pulp sediment quality, therefore, its hardness does not obviously change. Because the particle diameter of sawdust is far less than that of pulp sediment, the sawdust can be filled into pulp sediment to play a role of reinforcement. When the content of the sawdust goes over $30 \mathrm{phr}$, the excess sawdust can bring about gap and decrease the interaction between wood fibers and therefore, decrease the mechanical properties of sawdust/PS samples. Thus, $30 \mathrm{phr}$ sawdust was suitable for the sawdust reinforced pulp sediment.

Effects of used rubber powder on the sawdust/pulp sediment

The used rubber powder/sawdust/pulp sediment composites were studied, in which sawdust was used as reinforcement and rubber powder as toughening phase. The results are presented in Fig. 3. It can be seen that tensile stress and elongation-at-break values of the samples show the trend in rise after restrain, and then decrease with increasing the used rubber powder content. As the amount of used rubber powder was $10 \mathrm{phr}$, both mechanical properties show maximum value on the curves, but the hardness changed very little. The reason is that sawdust and pulp sediment belong to the same kind of materials, adding sawdust equals adding pulp sediment. Compared with the URP/PS curve, the peak value for the URP/sawdust/PS 

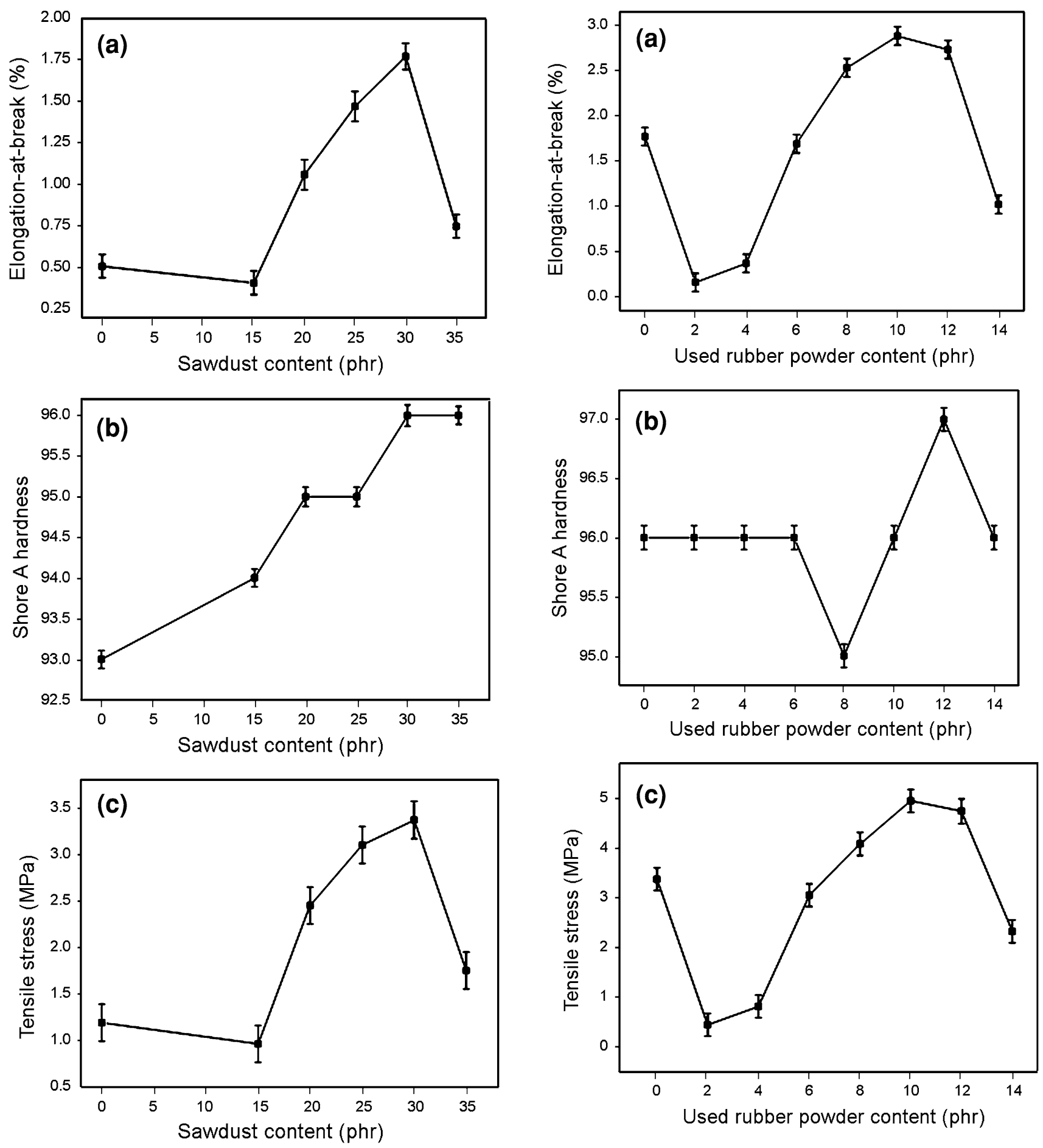

Fig. 2 Effect of sawdust content on the mechanical properties of pulp sediments: a elongation-at-break, b Shore A hardness, and c tensile stress (no rubber powder)

curve was only delayed. It is the case, when $10 \mathrm{phr}$ $(0.08 \times 130=10.4)$ of used rubber powder was added. Therefore, when the PS, sawdust, and URP are separately 100,30 , and $10 \mathrm{phr}$, respectively, the mechanical properties of sample is acceptable.

Fig. 3 Effect of used rubber powder content on the mechanical properties of the sawdust/pulp sediments (30/100): a elongation-atbreak, $\mathbf{b}$ Shore A hardness, and $\mathbf{c}$ tensile stress

In Figs. 1, 2, 3, it is found that mechanical properties of pure pulp sediment are poor in contrast with URP/PS and URP/sawdust/PS, but the mechanical properties of URP/PS are better than those of URP/sawdust/PS or sawdust/PS sawdust. Therefore, the best formulation is $100 \mathrm{phr}$ pulp sediments and $8 \mathrm{phr}$ used rubber pulp. 
Effects of curing conditions on the used rubber powder/ pulp sediment

The vulcanization is indispensable in composites process, and has the important effects on the performances of the composites. The effects of curing conditions (temperature, time, and pressure) on the mechanical properties are shown in Table 1. As the melting point of curing agent is at $140{ }^{\circ} \mathrm{C}$, the paper's flash point is $155^{\circ} \mathrm{C}$, so take curing temperature at $130-155^{\circ} \mathrm{C}$, but high temperature makes paper burn and low temperature cannot cure the sample. It can be seen that the sample properties are best at $150{ }^{\circ} \mathrm{C}$.

When curing temperature is below $150{ }^{\circ} \mathrm{C}$, the curing agent is not able to fully decompose, and so a little of used rubber powder cannot be cured. When curing temperature is over $150{ }^{\circ} \mathrm{C}$, due to reaching to the burning point of the paper, the sample properties declined. Thus, the best curing temperature of URP/PS lies at $150{ }^{\circ} \mathrm{C}$.

Similarly, when curing time is less than $15 \mathrm{~min}$, PS needs long time to dry, in this period of time, URP and curing agent cure incompletely, therefore, the specimen properties are poor. When curing temperature was more than $15 \mathrm{~min}$, partial dry pulp sediment was carbonized, lead to mechanical properties decline. Therefore, the best curing time is $15 \mathrm{~min}$.

Table 1 Effect of curing conditions on the properties of used rubber powder/pulp sediment

\begin{tabular}{llll}
\hline $\begin{array}{l}\text { Curing } \\
\text { condition }\end{array}$ & $\begin{array}{l}\text { Shore A } \\
\text { hardness }\end{array}$ & $\begin{array}{l}\text { Tensile stress } \\
(\mathrm{MPa})\end{array}$ & $\begin{array}{l}\text { Elongation- } \\
\text { at-break (\%) }\end{array}$ \\
\hline $\begin{array}{l}\text { Temperature }\left({ }^{\circ} \mathrm{C},\right. \\
13 \mathrm{MPa}, 15 \mathrm{~min})\end{array}$ & \\
130 & 96 & 2.5 & 1.2 \\
135 & 94 & 2.9 & 1.4 \\
140 & 93 & 3.4 & 1.8 \\
145 & 96 & 2.3 & 1.0 \\
150 & 97 & 5.2 & 3.0 \\
155 & 94 & 2.6 & 1.1 \\
Time (min, $\left.150{ }^{\circ} \mathrm{C}, 4 \mathrm{MPa}\right)$ & & \\
5 & 95 & 3.3 & 1.7 \\
10 & 94 & 1.0 & 0.4 \\
15 & 97 & 5.2 & 3.0 \\
20 & 94 & 3.5 & 1.8 \\
25 & 96 & 2.5 & 1.1 \\
Pressure $(\mathrm{MPa}$, & $\left.150{ }^{\circ} \mathrm{C}, 15 \mathrm{~min}\right)$ & \\
2 & 96 & 4.4 & 2.6 \\
3 & 96 & 4.9 & 2.8 \\
4 & 97 & 5.2 & 3.0 \\
5 & 97 & 5.8 & 2.0 \\
6 & 95 & 3.6 & \\
\hline
\end{tabular}

Pulp sediment $=100 \mathrm{phr}$, used rubber powder $=8 \mathrm{phr}$
In addition, when curing pressure was less than $5 \mathrm{MPa}$, URP and PS cannot be compacted closely and lead to the sample existing gap and structure loosening. When curing pressure is more than $5 \mathrm{MPa}$, on the one hand, it put the URP and PS together tightly, not easy heat diffusion and result in overheating char. On the other hand, the pulp fibers were ruptured under high pressure. Both would lead to decrease in properties of the sample. Thus, the best curing conditions are $150{ }^{\circ} \mathrm{C}, 5 \mathrm{MPa}$, and $15 \mathrm{~min}$.

\section{SEM and TEM analyses}

Figure $4 \mathrm{a}-\mathrm{d}$ shows the SEMs of pure PS, sawdust/PS, sawdust/URP/PS, and URP/PS samples, while Fig. $4 \mathrm{a}^{\prime}-\mathrm{d}^{\prime}$ shows TEM images of these samples, respectively. From the results of SEM and TEM images, it can be seen that the fibers in pure pulp sediment arrange disorderly in Fig. 4a, $\mathrm{a}^{\prime}$, and there exist larger gaps and looser arrangement. Figure 4b, b' exist irregular sawdust block, small clearance, looser arrangement, and unsmooth surface on the sawdust/ PS sample. Fibers in the sawdust/URP/PS arrange closely, and the sample has small gap as shown in Fig. 4c, while there exist three independent phase area such as 1 (URP phase), 2 (sawdust phase), and 3 (PS phase) in Fig. $4 \mathrm{c}^{\prime}$.

In Fig. 4d, there are compact structure and uniform arrangement in the sample, and better entanglement between wood fibers, while URP is evenly dispersed in the wood fiber in Fig. $4 d^{\prime}$, it may demonstrate excellent compatibility between the URP and PS. It can be explained that the fiber in the PS is longer, lead to entangling disorderly, and more and larger gaps. But the particle diameter of used rubber powder is smaller, it is easy to fill into the gap of fibers to have filler and compatibilizer function, makes sample structure compact, arrange uniform, and improve mechanical properties of URP/PS. Considering of the particle diameter of sawdust is greater than that of the URP, at the same time, sawdust and PS belong to the same kind of materials. Therefore, the compatibility of sawdust/ URP/PS is worse than that of URP/PS.

\section{Conclusion}

Used rubber powder modified PS composites were prepared and their curing conditions, mechanical properties, and morphology were investigated. It was found that when the used rubber powder/pulp sediment mass ratio was $8 / 100$, the used rubber powder/pulp sediment sample has smooth surface, high hardness, compact structure, uniform arrangement, and good compatibility. When the pulp sediment used as the matrix, sawdust as the reinforcement and used rubber powder as the toughening agent, the proper recipe of the composites was $100 \mathrm{phr}$ pulp sediment, 

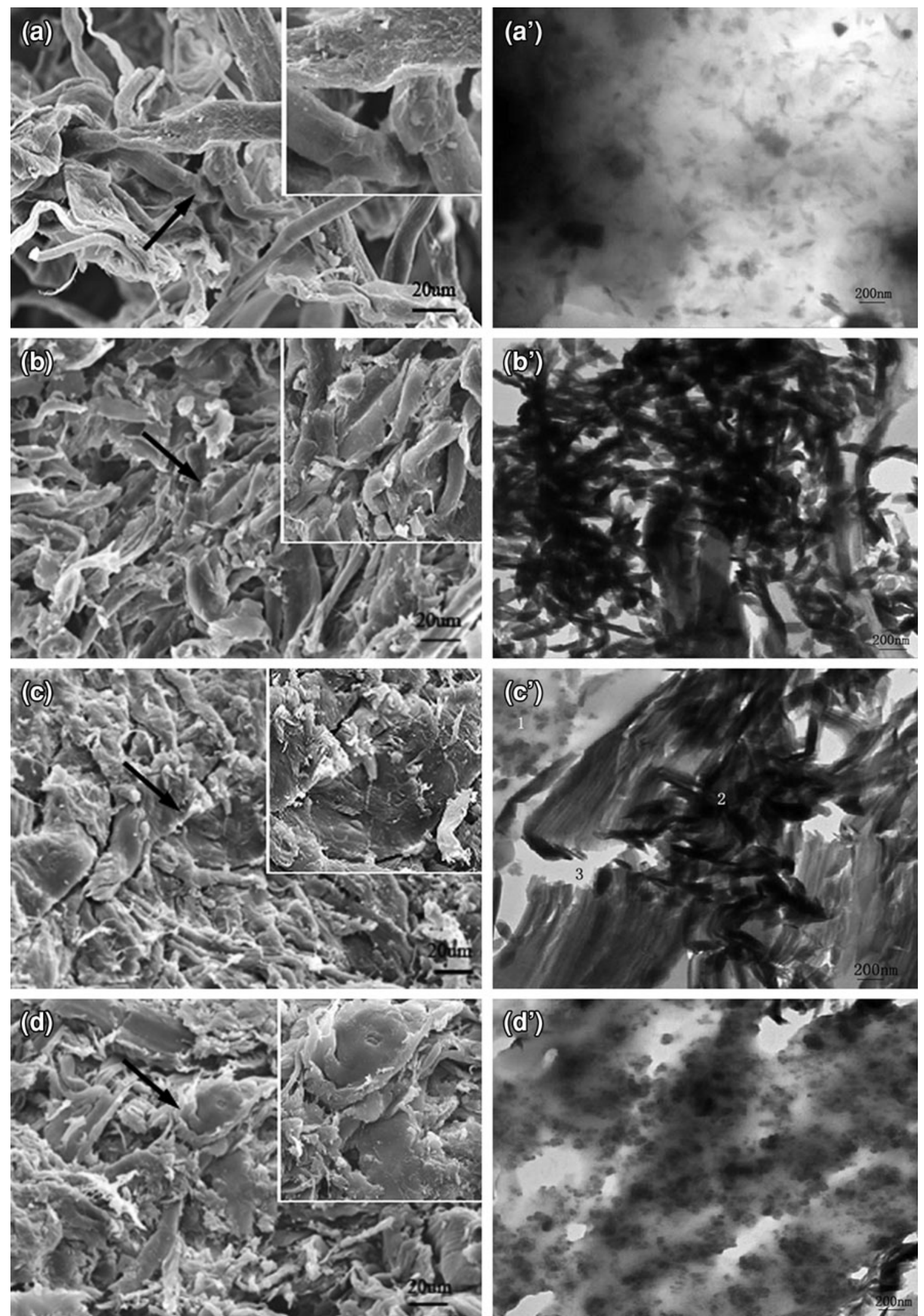

Fig. 4 SEM micrographs of: a Pure pulp sediments; b 100 phr pulp sediments and $30 \mathrm{phr}$ sawdust; c $100 \mathrm{phr}$ sediments, $30 \mathrm{phr}$ sawdust, and $10 \mathrm{phr}$ used rubber powder; and d $100 \mathrm{phr}$ pulp sediments and
8 phr used rubber powder, and TEM micrographs $\left(\mathbf{a}^{\prime}, \mathbf{b}^{\prime}, \mathbf{c}^{\prime}\right.$, and $\left.\mathbf{d}^{\prime}\right)$ of the same specimens 
30 phr sawdust, and 10 phr used rubber powder. Mechanical properties of the used rubber powder/pulp sediment were greater than those of pure pulp sediment and used rubber powder/sawdust/pulp sediment. The best curing conditions for the used rubber powder/pulp sediment composites are at $150{ }^{\circ} \mathrm{C}$ under $5 \mathrm{MPa}$ for $15 \mathrm{~min}$. The study on used rubber powder modified pulp sediment exploits a new way to recycle used rubber powder and pulp sediment, not only benefits environment refinement, but also reduces cost of sheet materials, and develops a new way for the economy and environment protection.

Open Access This article is distributed under the terms of the Creative Commons Attribution License which permits any use, distribution, and reproduction in any medium, provided the original author(s) and the source are credited.

\section{References}

1. Modolo R, Benta A, Ferreira VM, Machado LM (2010) Pulp and paper plant wastes valorisation in bituminous mixes. Waste Manage 30:685-696

2. Simonič M, Vnučec D (2012) Coagulation and UF treatment of pulp and paper mill wastewater in comparison. Cent Eur J Chem 10:127-136

3. Zhan P, Chen JN, He G, Fang GG, Shi YG (2010) Microbial dynamics in a sequencing batch reactor treating alkaline peroxide mechanical pulp and paper process wastewater. Environ Sci Pollut R 17:1599-1605

4. Lin YQ, Wang DH, Li Q, Huang LJ (2011) Kinetic study of mesophilic anaerobic digestion of pulp \& paper sludge. Biomass Bioenerg 35:4862-4867

5. Shen JC, Agblevor FA (2011) Ethanol production of semisimultaneous saccharification and fermentation from mixture of cotton gin waste and recycled paper sludge. Bioproc Biosyst Eng 34:33-43

6. Zhang LH, Champagne P, Xu CB (2011) Bio-crude production from secondary pulp/paper-mill sludge and waste newspaper via co-liquefaction in hot-compressed water. Energy 36:2142-2150

7. Wu WL, Chen DJ (2008) Mechanical and thermal properties of fly ash/reclaimed rubber powder composites improved by $\mathrm{KH}-$ 550 coupling agent. Int Polym Process 23:223-227

8. Kojima Y, Yoon SL (2008) Improved enzymatic hydrolysis of waste paper by ozone pretreatment. J Mater Cycles Waste 10:134-139

9. Obolkin VA, Potemkin VL, Khodzher TV, Golobokova LP, Filippova UG, Makukhin VL, Toda K, Takeuchi M, Obata T,
Khirota K (2010) Dynamics of sulfur-containing admixtures in the atmosphere around a point source-the baikal pulp and paper plant on the southeast coast of lake baikal. Atmos Ocean Opt 23:32-38

10. Lind EE, Grahn M (2011) Directional genetic selection by pulp mill effluent on multiple natural populations of three-spined stickleback (Gasterosteus aculeatus). Ecotoxicology 20:503-512

11. Zhu MX (2011) Problems and solutions about waste paper recovery and utilization in China (In Chinese). Recyc Resour Circul Econom 4:39-42

12. Kong J, Wang GR, Wang YP (2011) Research on the waste paper recycling status and methods (In Chinese). Resour Recyc 11:40-42

13. Huang F, Li KC (2009) Measurement of interfiber friction force for pulp fibers by atomic force microscopy. J Mater Sci 21:3770-3776

14. Nikonorov AM, Matveev AA, Reznikov SA, Arakelyan VS, Luk'yanova NN (2012) Results of multiyear studies on the dynamics of pollution of lake Baikal by polycyclic aromatic hydrocarbons in the area waste water discharge from the baikal pulp and paper plant. Dokl Earth Sci 443:361-364

15. Gu HB, Wang ZY, Li YQ, Wang XH, Chen WY (2010) Methods for inhibiting moulds growth on leather goods during transportation and storage. China Leather 39:14-17

16. Ruzene DS, Gonçalves AR (2007) Ethanol/water pulp enzymatic pretreatment: chemical and FTIR-PCA analyses. Chem Pap 61: 472-476

17. Singh YP, Dhall P, Mathur RM, Jain RK, Thakur V (2011) Bioremediation of pulp and paper mill effluent by tannic acid degrading enterobacter sp. Water Air Soil Poll 218:693-701

18. Khosravi M, Badalians Gholikandi G, Soltanzadeh Bali A, Riahi R, Tashaouei HR et al (2011) Membrane process design for the reduction of wastewater color of the mazandaran pulp-paper industry Iran. Water Resour Manage 25:2989-3004

19. Méndez A, Barriga S, Guerrero F, Gascó G (2011) Thermal analysis of growing media obtained from mixtures of paper mill waste materials and sewage sludge. J Therm Anal Calorim 104:213-221

20. Hamzeh Y, Ashori A, Mirzaei B (2011) Effects of waste paper sludge on the physico-mechanical properties of high density polyethylene/wood flour composites. J Polym Environ 19:120-124

21. Ohtsu Y, Yamada R, Urasaki H, Misawa T, Popescun S (2010) Development of a novel hybrid microwave-heater reactor for paper-based waste treatment. J Mater Cycles Waste 12:25-29

22. Méndez A, Barriga S, Saa A, Gascó G (2010) Removal of malachite green by adsorbents from paper industry waste materials thermal analysis. J Therm Anal Calorim 99:993-998

23. Morozova VV, Semenova MV, Rozhkova AM, Kondrat'eva EG, Okunev ON (2010) Influence of the cycle number in processing of cellulose from waste paper on its ability to hydrolysis by cellulases. Appl Biochem Micro 46:363-366 